\title{
PROJETO DE CRIAÇÃO DE UMA EMPRESA NO SETOR AGRÍCOLA: O CASO DA GREENNUTS
}

\section{PROJECT FOR THE CREATION OF A COMPANY IN THE AGRICULTURAL SECTOR: THE GREENNUTS CASE}

\author{
Luís Pereira $^{1}$ \\ Pedro Carvalho ${ }^{2}$
}

\begin{abstract}
Resumo: O presente projeto consiste num plano de negócio para a Greennuts, uma empresa de produção de bens alimentares que pretende conquistar um lugar no mercado alimentar. Os objetivos do projeto prendem-se com a avaliação económica e financeira do plano de negócio e consequente análise de viabilidade. Para tal, foi efetuado um estudo exaustivo de todas as variáveis que possam afetar o desenvolvimento do projeto. Este estudo foi feito através de uma revisão da literatura de alguns autores, destacando-se os artigos de Martino (2015) e Couceiro (2013). Posteriormente é apresentada uma análise de mercado, um estudo das políticas de implementação do negócio e da conjuntura económica nacional. A partir daqui, foram avaliadas as oportunidades e ameaças para a Greennuts e realçados os seus pontos fortes e fracos para que se possa estudar a integração da empresa na sua envolvência. Com base no levantamento de dados e no respetivo estudo, foi traçada a estratégia de desenvolvimento da Greennuts que contém todo o processo de formulação estratégica, desde a explicação do conceito de negócio, até à definição do melhor caminho para alcançar os objetivos. Finalmente, foi determinado com maior precisão, um conjunto de políticas de implementação do negócio que, assistidas das respetivas estimativas de custos e proveitos, fundamentam a análise de viabilidade económica e financeira realizada, afirmando-o como um projeto viável.
\end{abstract}

Palavras-chave: Agricultura; Pistacho; Plano de negócio.

\footnotetext{
${ }^{1}$ Diretor da Empresa Greennuts. E-mail: greennutslda@ gmail.com

${ }^{2}$ Docente na Escola Superior de Gestão do Instituto Politécnico de Castelo Branco. Email: pcarvalho@ipcb.pt
} 


\begin{abstract}
This project consists of a business plan for Greennuts, a food production company that aims to gain a place in the food market. The objectives of the project relate to the economic and financial evaluation of the business plan and consequent feasibility analysis. For this purpose, an exhaustive study was made of all the variables that could affect the development of the project. This study was done through a review of the literature of some authors, highlighting the articles by Martino (2015) and Couceiro (2013). Subsequently, a market analysis is presented, a study of the policies for implementing the business and the national economic situation. From here, the opportunities and threats for Greennuts were evaluated and their strengths and weaknesses were highlighted so that the integration of the company in its surroundings could be studied. Based on the data collection and the study, Greennuts' development strategy was drawn up, which contains the entire strategic formulation process, from the explanation of the business concept to the definition of the best way to achieve the objectives. Finally, a set of business implementation policies was determined with greater precision, which, based on the respective cost and income estimates, support the analysis of economic and financial viability, stating it as a viable project.
\end{abstract}

Keywords: Agriculture; Pistachio; Business Plan.

\title{
INTRODUÇÃO
}

Na entrada do século XXI, a perceção de que precisamos procurar uma convivência mais sustentável, pensando na qualidade de vida das futuras gerações, da espécie humana e das demais espécies que connosco compartilham o planeta Terra, passou a ser quase uma unanimidade, não obstante a multiplicidade de visões que o conceito de sustentabilidade abriga.

No final do século XX e início do século XXI, de acordo com Zylbersztajn et al. (1993), a agricultura passou a ser vista apenas com o enfoque das cadeias produtivas, ou seja, como um conjunto de operações interdependentes que, realizadas em uma dada sequência, resultam em um produto final a ser comercializado. Segundo Heredia et al. (2010), a estruturação dessas cadeias produtivas, pensadas como redes ou sistemas que interligam a produção agrícola, a transformação agroindustrial e a distribuição dos produtos finais, reforçou a perspetiva da industrialização da agricultura e dos sistemas agroindustriais, dando sentido ao termo agronegócio proposto por Davis \& Goldberg (1957, p. 2): 
“...a soma total das operações de produção e distribuição de suprimentos agrícolas, das operações de produção nas unidades agrícolas, do armazenamento, processamento e distribuição dos produtos agrícolas e itens produzidos a partir deles.".

Atualmente, o setor de agronegócio em Portugal cresce acima do resto da economia, as exportações acompanham este crescimento e têm um papel determinante neste trajeto de ascensão.

Inserida no agronegócio, a fruticultura é uma atividade agrícola que está a renascer no nosso país verificando-se uma enorme revitalização do setor que começa a integrar a fileira dos produtos com grande contributo no equilíbrio da balança comercial portuguesa.

Neste sentido e identificando uma oportunidade de crescimento e desenvolvimento no mercado nasce o projeto da Greennuts. Motivados pelos resultados positivos da economia agrícola e associando a paixão pela natureza e pelos frutos secos em geral, optámos por iniciar um projeto na cultura do pistácio por esta ser uma cultura inovadora em Portugal e por apresentar características que se adaptam às condições atualmente existentes em várias regiões do interior do País.

\section{AGRICULTURA}

Para Almeida (2007) a agricultura, como atividade do homem inserido na sociedade, só de uma forma imperfeita se pode enquadrar em definições formais. Uma definição sucinta, tal como "a agricultura é a arte de cultivar os campos", é de tal forma vaga e pouco informativa que está longe de poder transmitir a ideia da complexidade e dos objetivos da atividade. Além disso, na agricultura empresarial moderna, a arte, cada vez mais, cede o seu lugar à ciência. Definições mais elaboradas como a de Diehl (1984) afirmam que "a agricultura consiste no esforço para situar a planta cultivada nas condições ótimas de meio (clima, solo) para lhe tirar o máximo rendimento em quantidade e em qualidade". Esta definição, sendo elucidativa do ponto de vista técnico, peca por negligenciar o conceito de agricultura como atividade económica e social. Barros (1975) reforça e reformula admitindo que na realidade o objetivo económico da agricultura, num sistema de produção capitalista ou empresarial não é a maximização do rendimento, mas sim do lucro, o que, como se sabe da teoria microeconómica da produção, não coincide com o máximo rendimento. Por outro lado, numa agricultura de subsistência o objetivo é o de assegurar 
a alimentação do agregado familiar, o que se faz sem a utilização de fatores de produção adquiridos no mercado e sem a preocupação da adequação das plantas ao meio.

Foi também sugerido por Diehl (1984) que "a agricultura é a arte de obter do solo, mantendo sempre a sua fertilidade, o máximo lucro". Embora introduzindo o conceito da manutenção da fertilidade do solo, que serve o objetivo de obter produções regulares ao longo dos anos (sustentabilidade dos sistemas de agricultura), esta definição apenas se adequa aos sistemas capitalistas de produção. Além disso não refere quais os intermediários entre o solo e o lucro, pelo que pode ser utilizada sem grande esforço para as atividades extrativas.

Barros (1975), concorda com a definição sintética e expressiva proposta por René Dumont, que define a agricultura como: "... a artificialização pelo homem do meio natural, com o fim de o tornar mais apto ao desenvolvimento de espécies vegetais e animais, elas próprias melhoradas". O conceito de artificialização do meio engloba as técnicas culturais, independentemente do seu grau de aplicação.

Para Almeida (2007), a enorme dificuldade em definir agricultura, prende-se com complexidade de que se revestem as atividades humanas, que decorrem em determinado momento histórico, ambiente natural e contexto social. Na sua mais larga aceção a agricultura deve ser encarada como fenómeno social. Esta atividade tem de se adaptar às condições ecológicas e sociais, que variam de lugar para lugar, o que levou Barros (1975) a afirmar que a agricultura é, por excelência, o domínio da diversidade. Diversidade no enquadramento paisagístico, nos solos, no clima, na adaptabilidade das plantas cultivadas e dos animais domésticos e na presença de vegetação espontânea e animais selvagens. Diversidade nas atitudes e comportamentos dos homens, na riqueza material e estatuto social dos agricultores, no papel da agricultura na economia global. Diversidade na tecnologia disponível, no equipamento utilizado, no grau de utilização do potencial produtivo dos terrenos, nas estruturas fundiárias, na organização empresarial.

O conceito que uma sociedade tem da agricultura modifica-se quando se alteram as condições ecológicas e sociais referidas. Essa mudança está bem patente na evolução que o conceito "político" de agricultura tem sofrido nos últimos tempos. Durante milhares de anos a sociedade encarou a agricultura como uma atividade de subsistência, cujo objetivo primário era a produção de alimentos. Depois foi-se introduzindo na consciência 
coletiva a ideia da agricultura como atividade económica, sistemas de produção empresariais.

A empresarialização da agricultura em Portugal, expressa pelo crescimento do número de sociedades agrícolas, tem contribuído para o aumento da competitividade do setor, devido à adoção de processos de gestão mais profissionais e economias de escala (INE, 2013).

\subsection{O panorama agrícola em Portugal}

Há 60 anos, 48\% do emprego estava no setor da agricultura, silvicultura e pescas. Mais de 1,5 milhões de pessoas retiravam o sustento dessas atividades primárias, de baixo valor acrescentado, mal pagas, do trabalho de sol a sol. Nos campos e na orla piscatória do país a pobreza era uma constante muitas vezes traduzida em focos de miséria e fome. A iliteracia era esmagadora, a exploração dos trabalhadores também. Atualmente, a agricultura $\mathrm{e}$ as pescas passam mais despercebidas. Fortemente desmanteladas desde que Portugal aderiu à União Europeia (UE) (então CEE, em 1986), algumas atividades ficaram, em todo o caso, mais produtivas (Ribeiro, 2016).

Segundo o INE (2016), o setor absorve apenas 7,5\% da população empregada (343 mil pessoas no terceiro trimestre de 2015 , vale $2 \%$ do Produto Interno Bruto anual (PIB) (3,3 mil milhões de euros) quando em 1955 valia $27 \%$ da riqueza doméstica. No ano de 2015, apesar do peso muito modesto no PIB (devido às importações elevadas), o setor agroalimentar teve relevância nas exportações de bens, pesava $12 \%$ do total e cresceu (desde 2010) 6\% ao ano.

Por outro lado, segundo o GPP (2016), Portugal enfrenta desafios em matéria de êxodo rural e de envelhecimento da população. A idade média do produtor agrícola singular é de 64 anos, representando $52 \%$ do total os que têm 65 ou mais anos (apenas 2,5\% dos agricultores portugueses têm menos de 35 anos, contra 5,9 \% na UE-28). Continuamos com um nível demasiado baixo de instrução e qualificação da maioria dos produtores agrícolas e florestais: os produtores agrícolas singulares sem qualquer nível de instrução tinham, em 2013, um peso de 18,6 \% do total, ensino básico 22,0\%, secundário 5,8\% e superior 5,5\%.

Em aspetos territoriais, Portugal detém uma superfície de $89089 \mathrm{~km}^{2}$, dos quais $47 \%$ são terrenos agrícolas e $39 \%$ florestais e uma população de 10 milhões de habitantes, dos quais $34 \%$ vivem em zonas rurais e em que a população agrícola familiar (produtor e membros do seu agregado familiar, 
quer trabalhem ou não na exploração) representava, em 2013, 6,5 \% da população residente no País (GPP, 2016).

A Superfície Agrícola Utilizada (SAU) de Portugal é de cerca de 3,6 milhões de hectares (ha), dos quais $30 \%$ são ocupados por culturas temporárias, $20 \%$ por culturas permanentes e $50 \%$ por prados e pastagens permanentes. O número de explorações agrícolas, pouco mais de 305 mil, continua a verificar a tendência de diminuição, tendo-se reduzido de $13 \%$ em quatro anos, de 2009 para 2013. Em contrapartida, a dimensão média das explorações mantém o seu crescimento, tendo neste período passado de 12,1 para 13,8 ha de SAU. Em termos de estrutura, verifica-se um predomínio de explorações de pequena dimensão, representando cerca de $72 \%$ as com menos de 5 ha de SAU e que correspondem a $9 \%$ do total da SAU. Por sua vez, $67 \%$ da SAU concentra-se em $4 \%$ das explorações agrícolas, que têm uma dimensão superior a 50 ha. Quanto à estrutura da produção agrícola, 54,3\% do seu valor é relativo à produção vegetal, com destaque para as frutas e hortícolas que correspondem a $60 \%$ dos vegetais, e $41,2 \%$ à produção animal, realçando-se neste grupo o leite que representa $25 \%$ da produção animal, GPP (2016).

De acordo com a Comissão Europeia (2016), Portugal apresenta uma agricultura muito diversificada (Gráfico I) devido à diferente natureza dos solos e às suas características climáticas e paisagísticas. Nos produtos alimentares, é autossuficiente em pera, citrinos, maçã, vinho, ovos, mel, manteiga e leite, apresenta um bom nível de abastecimento próprio em azeite, arroz, carne de aves e de ovinos e caprinos e é muito deficitário em cereais.

\section{Gráfico I}

Componentes da produção (média de 2013-2015)

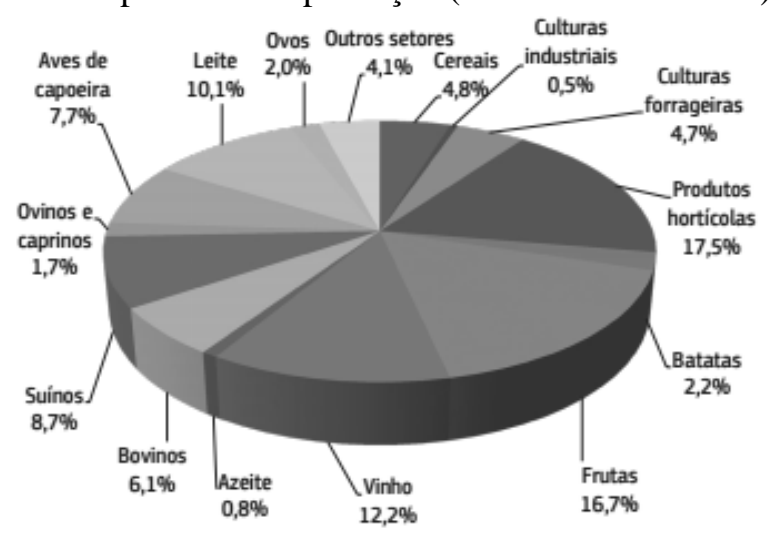

Fonte:- CE (2016)- A PAC no seu País 


\section{A PRODUÇÃO DE FRUTOS SECOS DE CASCA RIJA}

Segundo Silva (2013), em Portugal, as espécies mais conhecidas/consumidas pertencentes a esta categoria de frutos são a amêndoa, a noz, a castanha, o pinhão e a avelã. De facto, a Comissão das Comunidades Europeias (2002) indica que os frutos secos são cultivados há séculos nos países da região do Mediterrâneo e têm desempenhado um papel fundamental na proteção e manutenção do equilíbrio ambiental, social e rural de muitas regiões. Para Silva (2013), Portugal tem tido uma forte tradição na produção destes frutos, com um maior enfoque no pinhão e na castanha, e ligeiramente menor, nas nozes e nas amêndoas. A importância dos frutos de casca rija é tal, que foi uma das componentes fundamentais para elevar a dieta mediterrânica a Património Mundial e Imaterial da Humanidade pela Organização das Nações Unidas para a Educação, Ciência e Cultura (UNESCO, 2013).

De acordo com os dados apresentados pelo INE (2016), os principais frutos de casca rija produzidos em Portugal são a castanha, a amêndoa e a noz (Quadro I), tal como referiu Silva (2013) anteriormente.

\section{Quadro I}

Valores de produção de frutos secos de casca rija - Portugal

\begin{tabular}{|c|c|c|c|c|c|c|}
\hline \multirow[b]{3}{*}{ Culturas } & \multicolumn{3}{|c|}{ Stperficie } & \multicolumn{3}{|c|}{ Producio } \\
\hline & 2013 & 2014 & 2015 & 2013 & 2014 & 2015 \\
\hline & \multicolumn{3}{|c|}{ ha } & \multicolumn{3}{|c|}{$t$} \\
\hline \multicolumn{7}{|l|}{ Principais frutos de casca ria } \\
\hline Améndoo & 28480 & 28871 & 30150 & 4446 & 9034 & 10090 \\
\hline Avela & 391 & 392 & 393 & 337 & 352 & 360 \\
\hline Costang & 35168 & 35352 & 35595 & 24739 & 18465 & 27628 \\
\hline Noz & 2922 & 2946 & 3287 & 4609 & 4132 & 4062 \\
\hline
\end{tabular}

Para Rodrigues (2015), a produção de frutos secos de casca rija (noz e amêndoa) tem vindo a aumentar nos últimos anos - na ordem dos $62 \%$ entre 2002 e 2012 - ainda que a área se tenha mantido relativamente estável. Já no valor das exportações, sobressai uma evolução positiva muito mais acentuada, de tal forma que, em quantidade exportada, se registou um acréscimo de $123 \%$ e, em termos de valor exportado, um aumento surpreendente de $345 \%$.

De acordo com o autor, Portugal poderá aproveitar esta tendência mundial positiva. A existência de condições edafoclimáticas para isso e, igualmente importante, uma proximidade geográfica privilegiada com o segundo maior importador de amêndoas e nozes do mundo, a Espanha, são 
as principais vantagens para o País. Um pouco mais a norte encontramos a Alemanha e a Itália, como o primeiro e quarto maiores importadores do mundo, seguidos da França em sétimo lugar e da Holanda, em nono. Esta proximidade poderá ser capitalizada e os canais de escoamento trabalhados para aproveitar estes mercados.

A nível mundial, de acordo com dados do INC (2015) os maiores produtores de frutos secos de casca rija são os Estados Unidos da América (EUA), seguidos pela Turquia, Irão e China considerando frutos como o caju, a amêndoa, o pistacho, a noz e a avelã.

\subsection{A produção de pistacho}

Os primeiros fósseis do género Pistácio foram encontrados na ilha da Madeira e datam do Terciário. As diferentes espécies deste gênero difundiram-se por áreas muito diversas, no entanto a origem desta planta está localizada entre a Ásia Ocidental e Ásia Menor. O cultivo de pistacho é muito antigo, pois era conhecido e cultivado pelos egípcios, gregos e romanos. Foi introduzido na Itália, proveniente da Síria no primeiro século e mais tarde o seu cultivo espalhou-se para o resto dos países da bacia do Mediterrâneo. Na Península Ibérica, o cultivo do pistacho foi introduzido no tempo dos romanos, foi desenvolvido pelos árabes e desapareceu na Idade Média com os mouros, talvez pela eliminação das árvores masculinas improdutivas e com consequência direta na fertilização das árvores, (Couceiro et al, 2013).

De acordo com o autor, a reintrodução do cultivo de pistacho na Península Ibérica ocorreu na década de 80, mais precisamente em 1986, na região da Catalunha, Espanha. A partir da década de 90 foram adotadas várias medidas de desenvolvimento das culturas por diversos centros de investigação agrícola com o objetivo de melhorar as espécies até à data estudadas.

Atualmente, a superfície de cultura de pistácio em Espanha supera os 10000 ha, o nível médio de implementação é de 3000 ha/ano e no ano de 2015 a produção superou as $1500 t$, isto porque a maioria das culturas são muito jovens e ainda não se encontram em fase de produção . Na Península Ibérica, Castilla-La Mancha ocupa o primeiro posto quer em quantidade de produção quer em área de cultura, seguida pela região de Andaluzia. Outras comunidades, como Extremadura e Madrid começam a apostar na cultura deste fruto seco como uma alternativa de futuro, (Couceiro et al, 2013).

Segundo dados da FAO (2010), em superfície, o Irão é o 1..$^{\circ}$ produtor mundial com 330000 ha, seguindo-se os EUA com 85000 ha, Turquia 
com 52000 ha. A nível Europeu, a Grécia apresenta 5000 ha de superfície produtiva, Itália com 3500 ha e Espanha com 3500 ha (atualmente supera 10000 ha, como referido anteriormente).

No que diz respeito à quantidade produzida, os EUA lideram o ranking de produtores mundiais com 409000 toneladas (t) de produção, mais de $50 \%$ da produção mundial, seguindo-se o Irão com 180 000t e Turquia com 135 000t. No entanto, dados referentes a 2015 demonstram que as exportações são lideradas pelo Irão com aproximadamente 125000 , seguido dos EUA com aproximadamente 76 000t e China com aproximadamente 50 000t. As exportações totais são na ordem das 294 000t incluindo os restantes países produtores de menor escala. A china é o maior importador de pistacho do mundo com valores na ordem das 67 000t, seguindo-se o Vietnam e Alemanha com 60 000t e 29 000t respetivamente (INC, 2016).

Para Martino (2015), existe um forte crescimento na procura de pistacho por parte da China e de toda a UE, os dados indicam uma certa garantia de comercialização com preços de venda muito interessantes mesmo a longo prazo. O consumo per capita na UE é o mais alto do mundo, 193 gramas, posto isto seriam necessários cerca de 150000 ha de cultivo para suprir estas necessidades. No entanto a área de cultivo de pistacho na UE situa-se nos 19000 ha. Para o autor, o consumo irá aumentar de forma exponencial à medida que aumentar a oferta e os preços ao consumidor sejam menos especulativos, pois o pistacho promove grandes benefícios para a saúde, quer na prevenção de doenças cardiovasculares, quer pelas suas propriedades anticancerígenas.

Em Portugal a cultura do pistácio é inovadora, é tecnicamente recomendada para grandes superfícies de cultura, havendo ótimas condições de solo e clima em amplas regiões do Interior de Portugal (é uma cultura recomendada para solos bem drenados, ácidos a alcalinos, pedregosos e de baixa fertilidade. É adaptável ao clima continental, com muitas horas de frio invernal e muito calor de verão). Sendo a UE um grande consumidor cria uma oportunidade competitiva para os produtores de pistacho portugueses porque terão vantagem logística de fornecimento face aos grandes produtores mundiais. A rentabilidade da cultura indica do ponto de vista médio que a dimensão mínima de plantação para instalar um jovem agricultor é de 3 ha. O valor de investimento por ha na plantação (plantas, tutores, protetores, fertilização e correção de solo, a tração e a mão de obra) e equipamentos de limpeza de folhas, descasque e secagem variam 
de $16500 €$ a $22000 €$. Para além disso, acrescem os valores de construções, melhoramentos fundiários e outros equipamentos, os quais apresentam variações muito grandes em função da estruturação que a exploração apresenta. A recuperação do capital investido pode ser realizada entre 6 a 10 anos prevendo-se que as plantações durem mais de 50 anos em plena produção (Martino, 2015).

\section{A EMPRESA E O MODELO DE NEGÓCIO}

Constituída através de um contrato de sociedade comercial, por quotas, em Abril de 2016, a Greennuts é representada por três sócios gerentes e tem sede em Fernão Ferro, Setúbal. A atividade principal da empresa é desenvolvida na freguesia de Penamacor, concelho de Penamacor, distrito de Castelo Branco direcionada apenas para a produção de pistacho. No sentido de dar resposta a uma lacuna de mercado, a Greennuts aposta na especialização de produção de diversificadas espécies da árvore de pistácia, pretendendo adquirir conhecimentos chave para garantir uma qualidade de topo aos nossos clientes e conseguir produzir um produto de referência no mercado que este representa.

Como referido anteriormente, Penamacor é um concelho da Beira Baixa, pertencente ao Distrito de Castelo Branco. É limitado a Norte pelo concelho do Sabugal, a Sul pelo concelho de Idanha-a-Nova, a Oeste pelo do Fundão e a Leste pela Estremadura espanhola. É precisamente na freguesia de Penamacor que a Greennuts dispõe de um prédio rústico, Quinta da Falsa, com aproximadamente 12 ha onde será o centro de produção agrícola da empresa. Para além da produção de pistacho será aqui o ponto de armazenamento dos frutos, bem como o desenvolvimento das atividades primárias de investigação e melhoramento do fruto/produção. A sede da empresa situada no concelho do Seixal, direciona as suas atividades para a parte comercial e administrativa.

De acordo com o planeamento e objetivos estratégicos pré-definidos, a estrutura da empresa (Figura I) encontra-se dividida em três setores primordiais: Produção, Investigação e melhoramento, Comercial.

- Produção - Após a instalação do pomar, o processo contínuo de monitorização da produção consistirá na análise detalhada dos diversos processos e fatores que influenciam direta ou indiretamente a qualidade do produto acabado contribuindo assim para a melhoria do processo produtivo, o aumento da produtividade e a manutenção do nível competitivo na economia global em que estamos hoje inseridos. 
- Investigação - Neste setor, a empresa tem como objetivo principal a utilização de novas técnicas produtivas. Dos principais processos aqui realizados, destaca-se o aproveitamento natural dos rebentos de raiz e consequente aplicação de métodos de propagação a desenvolver para cada espécie de árvore utilizada na produção. Deste modo, partilhando as características genéticas da Planta-Mãe, estas novas plantas poderão ser utilizadas posteriormente para repovoação de eventuais perdas e ainda no plano de expansão de áreas de cultivo objetivado pela empresa.

- Comercial - Neste departamento, serão controladas todas as vendas da empresa bem como o controlo dos custos de produção e restantes processos administrativos.

\section{Figura I}

Estrutura Organizacional da Empresa

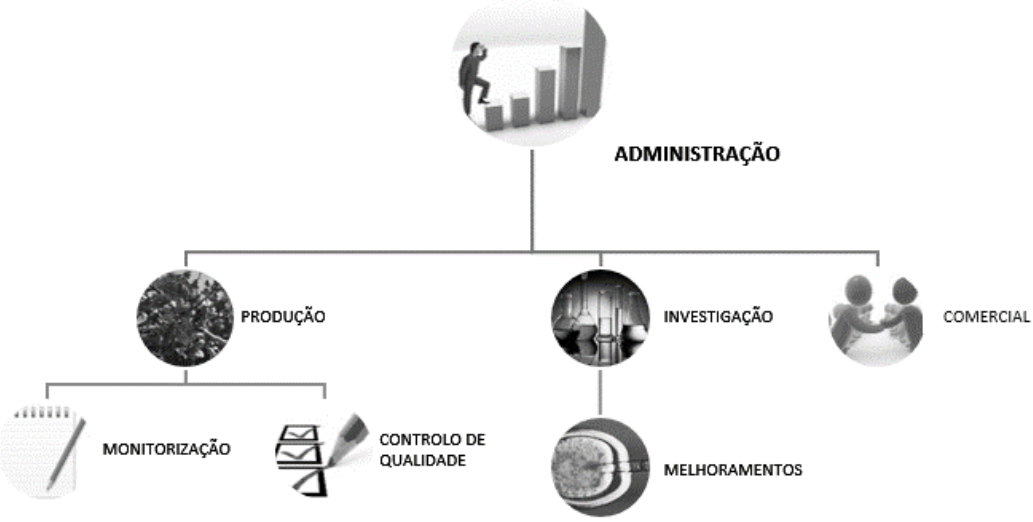

Fonte: Elaboração própria

Segundo o IAPMEI (s.d), com a aceleração do ritmo das mudanças tecnológicas, a globalização dos mercados e o aumento da agressividade concorrencial, as empresas têm que desenvolver novos métodos e estratégias para terem um sucesso sustentado nos negócios. No entanto, as crescentes pressões em relação aos resultados financeiros e à redução da duração dos ciclos de inovação dos produtos, deixaram os gestores sem tempo nem recursos suficientes para criar e desenvolver as competências internas necessárias. Logo, as empresas têm que ser mais competitivas a nível dos custos das suas operações. Para tal, necessitam de operar grandes 
reestruturações internas que, em regra, são demasiado morosas e pouco compensadoras em termos financeiros. A melhor solução passa pelas parcerias estratégicas. Este tipo de acordos permite que as empresas possam expandir e desenvolver as suas atividades, através de, num extremo, celebrar simples acordos de subcontratação e, no outro extremo, optar pelas fusões e aquisições. O conceito de «aliança estratégica» pode descrever qualquer tipo de parceria entre estes dois limites.

Tendo em conta as vantagens e benefícios das alianças estratégicas a Greennuts pretende estabelecer parcerias com:

- Fruystach Dry Flavors (Organização de Produtores de frutos secos);

- Cerfundão (Empresa de Embalamento e Comercialização de Cereja da Cova da Beira e outros frutos da região);

- IPMA (Instituto Português do Mar e da Atmosfera);

- ESACB-IPCB (Escola Superior Agrária de Castelo Branco Instituto Politécnico de Castelo Branco);

\section{PLANO ECONÓMICO-FINANCEIRO}

A empresa, que iniciou a sua atividade em Abril de 2016, começou a preparar a candidatura de apoio ao investimento no Programa de Desenvolvimento Rural 2020 (PDR2020) com um projeto cujo investimento total atinge o valor total de $341873,00 €$. Do financiamento do PDR2020 resulta um prémio à instalação no valor de $75000.00 €$, o qual é reembolsado em duas tranches, uma de $60000.00 €(80 \%)$ aquando da instalação e uma de $15000.00 €(20 \%)$ após o cumprimento do plano empresarial a 5 anos. Assim sendo, para o cálculo de incentivos considerase um valor total de investimento elegível de $341873.00 €$. Com este valor teremos um incentivo não reembolsável de $153843.00 €$ (45\%). No que diz respeito ao incentivo não reembolsável, este foi calculado de acordo com os investimentos indicados na Portaria n. ${ }^{\circ} 230 / 2014$, de 11 de novembro, alterada pela Portaria n. ${ }^{\circ}$ 301-B/2016 de 30 de novembro, a uma taxa de apoio de 45\%, conforme estipulado no Aviso de Abertura n 07/Ação 3.2/2016. Após verificação de adesão a uma Organização de Produtores (OP) Certificada é atribuído à empresa um subsídio não reembolsável no valor de 5000.00€. O Mapa de Demonstração de Resultados (Quadro II), sintetiza toda a informação relativa aos proveitos e custos da Greennuts entre o período 2017-2027, bem como a demonstração dos resultados líquidos em cada ano. 


\section{Quadro II}

Mapa de Demonstração de Resultados

\begin{tabular}{|c|c|c|c|c|c|c|c|c|c|c|c|}
\hline \multicolumn{12}{|c|}{ DEMONSTRAÇÃO DE RESULTADOS } \\
\hline & 2017 & 2018 & 2019 & 2020 & 2021 & 2022 & 2023 & 2024 & 2025 & 2026 & 2027 \\
\hline Vendas e serviços prestados & & & & 22924 & 52095 & 87693 & 118093 & 149093 & 180700 & 212925 & 245776 \\
\hline CMVMC & & & & 5627 & 5627 & 9378 & 12504 & 15630 & 18756 & 21882 & 25008 \\
\hline Fornecimento e serviços externos & 1427 & 17294 & 17467 & 18158 & 18854 & 19329 & 19994 & 20618 & 21214 & 21426 & 21640 \\
\hline Gastos com o pessoal & 314 & 3944 & 3944 & 4732 & 4732 & 4732 & 4732 & 4732 & 4732 & 4732 & 4732 \\
\hline EBITDA (Resultado antes depreciaçōe & -1741 & -21238 & -21411 & -5593 & 22882 & 54254 & 80863 & 108112 & 135998 & 164885 & 194396 \\
\hline Gastos/reversões de depreciação e aı & 3320 & 44569 & 44569 & 24407 & 19976 & 11623 & 2190 & 2190 & 2190 & 2190 & 1939 \\
\hline EBIT (Resultado Operacional) & -5060 & -65806 & -65979 & -29999 & 2906 & 42631 & 78672 & 105921 & 133808 & 162695 & 192457 \\
\hline Juros e rendimentos similares obtido & 125 & 361 & 0 & 166 & 87 & 894 & 1781 & 3061 & 4799 & 7707 & 10498 \\
\hline Juros e gastos similares suportados & 433 & 5192 & 5380 & 6020 & 6020 & 5501 & 4899 & 4297 & 3695 & 3093 & 2491 \\
\hline RESULTADO ANTES DE IMPOSTOS & -5368 & -70637 & -71359 & -35853 & -3027 & 38025 & 75554 & 104685 & 134912 & 167309 & 200464 \\
\hline Imposto sobre o rendimento do period & & & & & & 9506 & 18889 & 26171 & 32443 & 38714 & 50116 \\
\hline RESULTADO LÍQUIDO DO PERÍODO & -5368 & -70637 & -71359 & -35853 & -3027 & 28518 & 56666 & 78514 & 102469 & 128595 & 150348 \\
\hline
\end{tabular}

Os resultados indicam-nos que os primeiros cinco anos (2017-2021) apresentam resultados negativos devido ao investimento inicial e ao tempo médio de crescimento da planta até atingir produções significativas. A produção de pistácio, bem como outras culturas arvenses, necessita de períodos entre os 3 a 4 anos para iniciar o seu processo produtivo, dependendo da cultura em questão entrará em velocidade cruzeiro de produção quando a planta atinge entre os 6 e os 8 anos de idade. A partir do ano de 2022 a empresa estima atingir um resultado liquido positivo no valor de $28518.00 €$, apontando para um crescimento gradual nos anos seguintes estimando valores acima dos $150000.00 €$ por ano a partir do ano de 2027.

Analisando o Balanço Previsional da Greennuts (Quadro III), observamos a redução do risco financeiro da empresa a partir do ano de 2024, altura em que a autonomia financeira da empresa representa um valor de $56 \%$ e uma solvabilidade total de $228 \%$. 


\begin{tabular}{|c|c|c|c|c|c|c|c|c|c|c|c|}
\hline \multicolumn{12}{|c|}{ BALANÇO PREVISIONAL } \\
\hline & 2017 & 2018 & 2019 & 2020 & 2021 & 2022 & 2023 & 2024 & 2025 & 2026 & 2027 \\
\hline \multicolumn{12}{|l|}{ ACTIVO } \\
\hline Activo Não Corrente & 308571 & 293984 & 249416 & 225009 & 205033 & 193410 & 191220 & 189029 & 186839 & 184649 & 182709 \\
\hline Activo corrente & 28116 & 38642 & 20612 & 31035 & 29243 & 72852 & 119979 & 186860 & 276691 & 425076 & 567661 \\
\hline TOTAL ACTIVO & 336687 & 332627 & 270028 & 256044 & 234276 & 266262 & 311199 & 375889 & 463530 & 609725 & 750370 \\
\hline TOTAL DO CAPITAL PRÓPRIO & 148475 & 142838 & 71479 & 35626 & 32600 & 76118 & 132784 & 211298 & 346210 & 474805 & 625153 \\
\hline \multicolumn{12}{|l|}{ PASSIVO } \\
\hline Passivo não corrente & 188030 & 188030 & 188030 & 218030 & 199227 & 177424 & 155621 & 133818 & 112015 & 90212 & 68409 \\
\hline Financiamentos obtidos & 188030 & 188030 & 188030 & 218030 & 199227 & 177424 & 155621 & 133818 & 112015 & 90212 & 68409 \\
\hline Passivo corrente & 182 & 1759 & 10519 & 2388 & 2450 & 12720 & 22794 & 30773 & 5305 & 44708 & 56809 \\
\hline Fornecedores & 136 & 1643 & 1660 & 2249 & 2311 & 2708 & 3065 & 3418 & 3768 & 4083 & 4397 \\
\hline Estado e Outros Entes Públicos & 46 & 115 & 115 & 139 & 139 & 10012 & 19729 & 27356 & 1536 & 40625 & 52411 \\
\hline TOTAL PASSIVO & 188212 & 189789 & 198549 & 220418 & 201677 & 190144 & 178415 & 164591 & 117320 & 134920 & 125218 \\
\hline TOTAL PASSIVO + CAPITAIS PRÓPRIOS & 336687 & 332627 & 270028 & 256044 & 234276 & 266262 & 311199 & 375889 & 463530 & 609725 & 750370 \\
\hline
\end{tabular}

Fonte: Adaptado do website www.iapmei.pt

A evolução positiva, observada no plano de negócio da empresa, de todos os indicadores, em especial a partir do ano de 2024, decorre da evolução da produção principal da atividade da empresa, o pistacho, que atingirá a velocidade cruzeiro de produção entre o ano de 2025 e o ano de 2027.

\section{CONCLUSÃO}

O presente negócio foi projetado para se submeter aos apoios governamentais e da UE no âmbito do PDR2020. A criação destes apoios surge como resultado de uma das prioridades do desenvolvimento económico em Portugal que passa pela reabilitação do tecido produtivo no setor agrícola. Desta forma, o PDR2020 através de apoios a fundo perdido cofinancia investimentos na atividade agrícola, florestal e animal.

Através do plano económico-financeiro apresentado neste trabalho, demonstrou-se que perante o cenário mais conjeturável, o projeto de investimento referente à instalação de uma plantação de pistácio no montante global de $341873.00 €$, apresenta viabilidade económica. O caso de estudo apresenta um Valor Atual Líquido de 237.565.00 €, uma Taxa Interna de Rentabilidade de $14 \%$ e um período de recuperação do investimento de 6 anos. Em sequência da extrapolação de dados à generalidade dos projetos conclui-se que o número de anos mínimo para que a cultura de pistácio seja rentável é de aproximadamente cinco anos. 
De entre os vários produtos agrícolas, o pistacho, é dos que proporciona uma maior rentabilidade a longo prazo, pois a longevidade de uma árvore de pistácio em plena produção pode chegar aos 50 anos. No entanto a rentabilidade máxima ocorre entre o oitavo e o décimo ano onde os custos médios da exploração diminuem considerando a idade adulta da árvore e consequentemente um menor aporte de nutrientes e tratamentos que são essenciais na fase de desenvolvimento.

Conforme referido anteriormente, a produção e comercialização do pistacho no ocidente Europeu encontra-se numa fase inicial, a procura mantém -se elevada e a oferta é insuficiente. A par disto há uma procura por parte dos produtores em Portugal para se associarem, facto que vem trazer vantagens no poder de negociação com os "grandes clientes" e mesmo para enfrentar a possibilidade de exportação. Aliado a esta realidade há uma crescente preocupação dos consumidores com a saúde e o bem-estar, resultando num maior cuidado com a alimentação o que perspetiva o contínuo crescimento da procura.

O facto de este produto ser muito apreciado nalguns países da UE com grande poder de compra, nomeadamente a Alemanha, Reino Unido, Holanda e países nórdicos e que o importam essencialmente do Irão e EUA, países não pertencentes à UE, cria uma oportunidade de entrada no mercado da distribuição deste fruto seco em território intracomunitário, pois a importação de outros continentes está sujeita a custos com taxas alfandegárias e custos elevados no transporte, o que, naturalmente, resulta no encarecimento unitário do produto.

A produção em Portugal tem pelo menos estas duas vantagens apresentadas em relação aos principais exportadores mencionados, por isso, ganhando escala através da OP já criada, embora com funcionamento condicionado, a exportação para estes países da UE referidos é uma possibilidade e uma oportunidade no horizonte do empreendedor deste negócio.

Se tal vier a suceder, este negócio dará um contributo às exportações do país, contribuindo dessa forma para o aumento de riqueza do mesmo. Caso contrário, mesmo comercializando apenas em Portugal, contribuirá para baixar as importações, uma vez que apesar de não estar ao nível dos países da UE referidos em termos de consumos, a verdade é que Portugal também importa este produto, uma vez que a procura supera a oferta. 


\section{FONTES E BIBLIOGRAFIA}

Almeida, D. (2007). Conceito de agricultura. Consultado em 20 de Outubro de 2016, de http://dalmeida.com/ensino/pa-conceito.htm

Barros, H. (1975). Os grandes sistemas de organização da economia agrícola. $1^{a}$ ed. Lisboa: Livraria Sá da Costa Editora.

CCE - Comissão das Comunidades Europeias, (2002). Comission Staff Working Paper, Analysis of the nut sector. In SEC (2002) 797. Bruxelas.

CE - Comissão Europeia (2016). A PAC no seu País. Consultado em 12 de Setembro de 2016, de

https://ec.europa.eu/agriculture/sites/agriculture/files/cap-in-yourcountry/pdf/pt_pt.pdf

Couceiro, F., Villaseñor, G., López, C., Elvira, M., López, P., \& Francisco, R. (2013). El cultivo del pistacho. Madrid: Ediciones Mundi-Prensa.

Davis, H., Goldberg, A. (1957). A Concept of Agribusiness. Boston: Harvard University Graduate School of Business Administration.

Diário da República de 2 de Janeiro de 2017, I Série, n²/2017, pp. 12-15 (2017). Procede à segunda alteração à Portaria n..$^{\circ}$ 31/2015, de 12 de fevereiro, com a redação dada pela Portaria n. ${ }^{\circ}$ 249/2016, de 15 de setembro que estabelece o regime de aplicação da ação n. ${ }^{\circ} 3.1$, do Programa de Desenvolvimento Rural do Continente.

Diehl, R. (1984). Agricultura geral. Lisboa: Clássica Editora.

FAO - Food and Agriculture Organization of the United Nations (2010). FAOSTAT database - Production and crops. Rome: FAO.

GPP (2016). Agricultura, Silvicultura e Pescas - Indicadores 2016. Lisboa: Gabinete de Planeamento, Políticas e Administração Geral;

Heredia, B., Leite, S., Palmera, M., (2010). Sociedade e Economia do "Agronegócio" no Brasil. Revista Brasileira de Ciências Sociais, v. 25, n. 74, 2010.

IAPMEI - Instituto de Apoio às Pequenas e Médias Empresas e à Inovação. (s.d.). Consultado em 15 de novembro de 2016, de https://www.iapmei.pt;

INC - International Nut and Dried Fruits Council (2015). INC Statistics Database. Consultado em 12 de Março de 2017, de https://nutfruit.org/what-we-do/industry/statistics

INC - International Nut and Dried Fruits Council (2016). Nuts \& Dried Fruits Statistical Yearbook 2016/2017. Spain: INC. Consultado em 24 de Março de 2017, de https://www.nutfruit.org/files/multimedia/1510229514_1497859419_ Statistical_Yearbook_2016-2017.pdf 
INE, I. P. (2013). Inquérito à Estrutura das Explorações Agrícolas 2013. Lisboa: Instituto Nacional de Estatística, I.P.

INE, I. P. (2016). Estatísticas agrícolas 2015. Lisboa: Instituto Nacional de Estatística, I.P.

Martino, J. (2015). Pistacho - Oportunidade de Futuro. Revista Voz do campo. Consultado a 10 de Janeiro de 2016, de http://www.espacovisual.pt/espa\%C3\%A7o-visual-est\%C3\%A1-lan\%C3\%A7ar-umanova-empresa-conhe\%C3\%A7a-fruystach-revista-voz-do-campo.

Ribeiro, L. (2016). Portugal será de novo um país agrícola? Europa vê grande potencial. Dinheiro Vivo. Consultado em 29 de Junho de 2017 de https://www.dinheirovivo.pt/economia/portugal-sera-de-novo-umpais-agricola-europa-ve-grande-potencial

Rodrigues, N. (2015). Frutos de casca rija: uma oportunidade. Revista Vida Rural. Consultado em 19 de Junho de 2017 de http://www.consulai.com/images/Artigo/Artigo_Frutos_Casca_Rija.p df

Silva, A. (2013). O consumo de frutos secos e o efeito na saúde. Ordem dos Engenheiros. Consultado em 19 de Julho de 2017 de http://www.ordemengenheiros.pt

UNESCO - Organização das Nações Unidas para a Educação, a Ciência e a Cultura (2013). Oitava Sessão do Comitê Intergovernamental (8.COM). Consultado em 9 de Junho de 2017 de https://ich.unesco.org/en/8com

Zylbersztajn, D., farina, O., Santos, C. (1993). O sistema agroindustrial do café: um estudo do agribusiness do café como a chave da competitividade. Porto Alegre: Ortiz. 